\title{
Research on Construction Lean SCM in IOT Environment
}

\author{
Lianyue Wang* \\ School of Management, Qingdao Technological University, Qingdao, 266520, China \\ ${ }^{*}$ Corresponding author
}

\begin{abstract}
Economic globalization and the integration process has led to competition among construction enterprises become increasingly fierce, which are adjusting their development strategies and efforts to seek for the knowledge economy and network environment to promote enterprise survival and development, enhancing the competitiveness of enterprises in the new business management models and ideas. This paper applies the Internet of things into construction lean supply, demonstrates the applicability, and puts forward the lean organization, lean procurement and lean inventory strategy design the IOT management platform.
\end{abstract}

Keywords-the internet of things; management platform; construction lean SCM; lean inventory; lean procurement; lean organization

\section{INTRODUCTION}

As the construction industry increasingly flourish, the traditional construction project management pattern already could not adapt to its development. So a method to increase the entire efficiency is urgently needed, which could solve the time, cost, quality problems existing in our country's project management and can improve enterprise's market competitiveness. Lean supply chain is a new and advanced construction management method that is suitable in the modern construction project management[1][6]. It put the lean thinking used widely in the manufacture profession into construction project management, and make a lean management from a perspective of the entire life cycle. Its essence is to eliminate the waste and to maximize the construction project value[2]. This paper applies the Internet of things into construction lean supply chain, start from lean organization to lean customer services, which from the entire life cycle. Both realize the internal lean management and realize the external lean management, the content as follows:

- Lean organization. In the supply chain environment, broken the boundaries of functional departments, linked the different production activities the internal enterprise, created a continuous flow of value chain, which realize the profit maximum and meet the customer needs.

- Lean procurement. In the construction process of the building products, building materials in the proper quantity and quality, at the right time and place to provide the required component project, which achieve the goal of materials lean procurement[7].

- Lean inventory. Because of the complexity and schedule of the project, construction enterprises and suppliers sharing-information that adjust the real-time inventory and supply situation of the enterprise to avoid the backlog of material reserves and repetition[4].

- Lean customer personalized service. The final product of construction delivered to the customer, which accept customer complaints and project improvement suggestions and accept the final product of reverse tracking management are promoted the customer value.

\section{IOT AND THE CONSTRUCTION LEAN SUPPLy CHAIN}

\section{A. The Internet of Things Improve The Perceptual Real-time Information Sharing}

The construction should be established unified standard, high maneuverability and the global shared information platform realize the lean management.[2] IOT can integrate internal information and external information, summary to the supply chain management information platform, provide the perceive information to the each node enterprise in the first time, knowledge of product, enterprise and supply chain. Understand customer requirements in timely and effective communication and available sharing of information to achieve orderly interaction of the internal management and external management.

\section{B. “The Cloud” Highlights the Real-time Sensation of Information}

It is the very important the real time, diversity and richness of information in lean supply chain management environment, especially each node enterprise should focus on the market, also to focus on upstream and downstream of other enterprises in order to response to customer demand change in time[2][7]. The advantages of the Internet of things is multifaceted and obtained information through various channels, through largescale sensor network and terminal collection the information from all kinds of infrastructure and access object, sent to the cloud for storage, computing and processing, which provide decision support for lean supply chain management.

\section{Sea Calculation To Enhance Information Accuracy and Fidelity}

Information distortion leads to the supply chain "bullwhip effect"[6]. The sea calculation mode of IOT makes the each link of supply chain can have self-organization, the calculation, the feedback function make the supply chain management system more intelligence through information exchange, more 
powerful ability of information processing, improve information accuracy, reduce the distortion.

\section{RESEARCH ON CONSTRUCTION LEAN SCM IN IOT ENVIRONMENT}

Construction lean supply chain is realize internal and external lean, realize the entire life cycle of the building product, realize the sharing-information, monitor the quality of building materials and trace the materials of suppliers based on IOT, which implement the lean organization, inventory, purchasing, and customer service.

\section{A. Lean Organization------the IOT Internal Management Platform}

Building enterprise internal departments unable to form the lean management of the internal activity because information isolated island phenomenon is serious[2][3]. Need to review all activities within the enterprise, optimize the core activities, and strengthen the coordination of each department which realize the real-time communication of department.

Construction enterprises establish the internal platform based on IOT, quickly completed the integration of information, and integrated the each department information send to internal platform, department can sensor information in the first time. According to the actual situation of the project, the budget department should make reasonable quantity calculation and accurate materials demand planning, project department should pay more attention to innovation, purchasing department should be gradually developed to a long term strategic partner and accurate procurement, decrease the internal waste to realize the lean management in the construction enterprises.

- Lean Procurement and Lean Inventory----the IOT external management Platform

- Lean procurement. Construction enterprises need to purchase thousands of materials, so need to lean procurement[7]. Through the IOT platform, the enterprise forecast the final product material to suppliers in the supply chain, on the basis of full information sharing between the two sides, supplier able to respond according to their ability to supply. Construction enterprises can realize recently sharing of material planning and inventory with suppliers, suppliers can increase the visibility of the enterprises demand, according to the procurement planning and the goods order to improve the accuracy and timeliness based on IOT platform, which can be delivered goods in the proper quantity and quality, at the right time and place is achieve the goal of lean procurement[6].

- Lean inventory. Construction enterprises need to decrease inventory in order to avoid "bullwhip effect" in the supply chain, which require suppliers can accurately understand the inventory of construction enterprises[4]. According to inventory realize delivery materials in time and optimize the transport route, which establish the platform based on IOT to solve the problems all of above. Design the IOT inventory management platform real-time transport information between construction enterprise and supplier. Suppliers can able to reasonable arrangement and distribution construction materials, monitor the real-time transportation and optimize the transport route in the process of distribution, which solve the goal of lean inventory.

\section{B. Lean Customer Service-----the IOT Customer Management Platform}

Customer Relationship Management is inevitably becoming an important approach, in front of the increasingly normative and fiercely competitive construction market. Construction enterprises understand the customers personalized needs and meet customers personalized needs, maintain customer loyalty and customer retention rate, ameliorate customer value, exalt enterprise core construction enterprises can able to understand and percept the customer information in the first time[5], design the IOT customer management platform, receive the customer the complaint and suggestion, improve the final building quality, maximum optimize the customer value.

\section{THE MOdELING OF CONSTRUCTION LEAN SUPPLY CHAIN BASED ON IOT}

IOT can realize integration of internal and external information, transmit the information to the IOT information platform each other, which each enterprises can accurately sense information of the inventory, procurement and customer service. As shown in Figure 1.

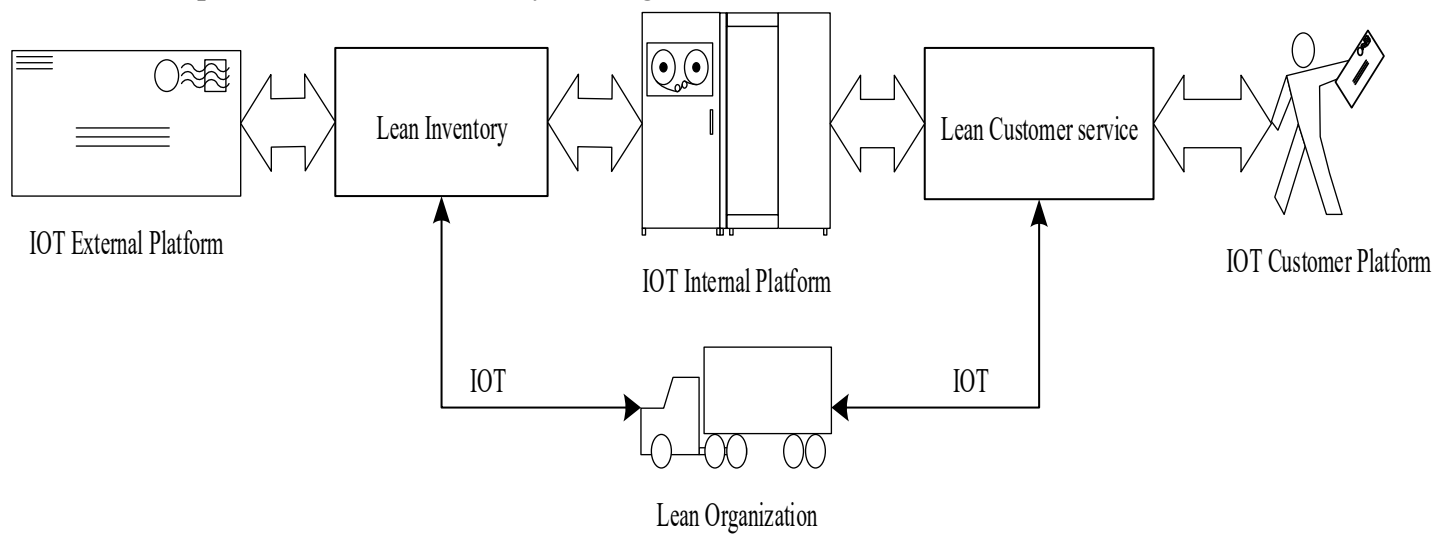

FIGURE I. THE MODELING OF CONSTRUCTION LEAN SUPPLY CHAIN 


\section{SUMMARY}

Through the study of this article enrich construction lean supply chain management in theory and provide enterprises in lean supply chain with theoretical basis and reference application value to improve lean supply chain level by IOT management platform. Design the IOT management platform realizes the real-time information exchange and sharing, establishes flexible and dynamic lean construction supply chain system, further promote integration and development between the Internet of things and construction lean supply chain, indicate the direction for the development of construction lean supply chain.

\section{ACKNOWLEDGEMENTS}

The research work was supported by Natural Science Foundation of Shandong Provincial under Grant No. ZR2012GL06.

\section{REFERENCES}

[1] Feng Shizhang, Liu Yisheng. Theory System Research of Lean Construction, J. Project Management Technology. 3(2008) 18-23.

[2] Gregory A.Howell. Lauri Koskela, Reforming Project Management: The Role of Lean Construction. IGLC. Brighton. UK. 2000.

[3] Mohammed Fadhil Dulaimi, Caroline Tanamas. The Principles and Applications of Lean Construction in Singapore. 2000.

[4] Yong Shengyuan. Research on Inventory Management Platform. Chengdu: Southwest jiaotong University, 2007.

[5] Pan yanli. Research of Customer Relationship Management in Construction Enterprise. Tianjin: Tianjin University, 2010.

[6] Sunil Chopra, Peter Meindl. Supply Chain Management Strategy, Planning, and Operation, Third ed., TSINGHUA UNIVERSITY PRESS, Beijing, 2010.

[7] Dong, Yan. Just-in-time purchasing and supply: A supply chain analysis. University of Maryland, College Park, 1998. 